\title{
Life-span and Senescence in Podospora anserina: Effect of Mitochondrial Genes and Functions
}

\author{
By LÉON BELCOUR* AND ODILE BEGEL \\ Centre de Génétique Moléculaire, C.N.R.S., 91190 Gif-sur-Yvette, France
}

(Received 29 June 1979; revised 1 November 1979)

\begin{abstract}
The life-span of a mitochondrial mutant of Podospora anserina resistant to chloramphenicol was at least five times that of isonuclear chloramphenicol-sensitive strains. This property was maternally inherited. A study of the segregation of heteroplasmic mycelia showed that, in addition to the mitochondrial alleles $\operatorname{cap}^{\mathrm{r}} I / c^{\mathrm{s}} \mathrm{s}{ }^{8} I$, another cytoplasmic factor, whose nature is discussed, controlled the life-span. Cycloheximide decreased the life-spans of all the strains studied, whereas they were greatly increased by chloramphenicol and ethidium bromide. Chloramphenicol seemed to act mainly by lowering the probability of commitment to senescence, while ethidium bromide seemed to affect both the commitment probability and the incubation period. Furthermore, chloramphenicol and ethidium bromide were able to rejuvenate senescent mycelia. These results are discussed in connection with previous results on the mitochondrial origin of senescence in Podospora anserina.
\end{abstract}

\section{INTRODUCTION}

Senescence in the fungus Podospora anserina has previously been shown to be under cytoplasmic control (Rizet, 1957; Marcou \& Schecroun, 1959; Marcou, 1961; Smith \& Rubenstein, $1973 a, b)$. More recently, the possible involvement of mitochondria in this phenomenon has been investigated (Smith \& Rubenstein, $1973 a$; Tudzynski \& Esser, 1977). Mainly on the basis of genetical results, we proposed a precise hypothesis about the origin of senescence in Podospora anserina: senescence would result from mitochondrial mutations similar to the well-known rho suppressive mutations of yeast (Belcour \& Begel, 1978). This hypothesis received some preliminary support from the study of mitochondrial DNA isolated from senescent mycelia. This DNA was shown to be modified in its restriction pattern, and a multimeric set of circular DNA molecules was found when DNA was extracted from senescent cultures (Cummings et al., 1978, 1979b).

In this paper, we show that a mitochondrial chloramphenicol-resistant mutant cap $I$ (Belcour \& Begel, 1977) displays a greatly increased life-span. In order to investigate whether physiological alterations of mitochondrial functions could also modify the life-span, we studied the effect of chloramphenicol (CAP) and ethidium bromide (EB) and compared the action of these drugs with that of cycloheximide (CHX) which inhibits cytoplasmic but not mitochondrial syntheses. The results show that CAP and EB, but not CHX, are able not only to increase the life-span of wild-type strains but also to rejuvenate senescent mycelia. The significance of these results is discussed in relation to the hypothesis of a mitochondrial determination of senescence.

\section{METHODS}

Strains. The following strains of Podospora anserina, a filamentous heterothallic ascomycete closely related to Neurospora crassa, were used: wild-type $s$ strains of minus and plus mating-type $(m t-\mid m t+)$ 
(ATCC 36611 and 36612, respectively); wild-type $A$ strains kindly provided by Dr D. Marcou; strains designated $(A) s$, carrying the cytoplasm of the wild-type $A$ strain and a nuclear genome closely related to that of the wild-type $s$ strain, resulting from five generations of back-crosses using the $A$ strain as the female parent and the $s$ strain as the male parent.

The following markers were used: $s p 37$ is a nuclear mutation, isolated by J. M. Simonet, determining white mycelium and spores; $\operatorname{cap}^{r} I$ is a mitochondrial CAP-resistant mutation isolated in the wild-type strain $s$, whose phenotypic properties and genetical behaviour have already been described (Belcour \& Begel, 1977). Briefly, its elongation rate is about $90 \%$ of that of the isonuclear wild-type strain, its cytochrome spectrum almost completely lacks the cytochrome $a a_{3}$ peak and its respiration is mostly cyanide-resistant.

Chemicals. Cycloheximide was from Sigma and ethidium bromide from Serva (Heidelberg). Chloramphenicol was either from Serva or Roussel-UCLAF (Paris); both gave identical results.

Culture conditions. Medium prepared from corn-meal extract (Esser, 1974) was used in all experiments and was supplemented with ammonium acetate (for spore germination) or with CAP, EB or CHX added after sterilization. Crosses were carried out at $27^{\circ} \mathrm{C}$, extent of growth was measured at $30^{\circ} \mathrm{C}$ and storage was at $4{ }^{\circ} \mathrm{C}$.

Measurement of life-span. Parallel cultures inoculated with mycelium taken straight from a germinating ascospore (and stored at $4{ }^{\circ} \mathrm{C}$ ) were grown in culture tubes $(36 \mathrm{~cm} \times 1.8 \mathrm{~cm}$ i.d.) containing solid corn-meal medium and kept in the dark. Inoculation of tubes and transfers were made with implants of about $10 \mathrm{~mm}^{2}$. The life-span of a strain was defined as the mean length of growth in parallel cultures between the point of inoculation and the arrested edge of the senescent culture. For strains showing very extended growth, it was not always possible to make exact measurements. The life-span was underestimated for several reasons: (i) some cultures had still not stopped growing when this paper was written; (ii) some cultures acquired the 'incolore' mutation, which is known to be correlated with increased life-span (Rizet, 1953), or were lost by contamination during transfers; (iii) in some cases, cultures were discontinued before they reached senescence.

Crosses. Sexual crosses were carried out by spermatization, i.e. by pouring on to a homothallic mycelium (female) a suspension of micro-conidia obtained from a culture of the opposite mating-type. In this way, no cytoplasmic mixing was allowed between the two parental strains.

For cytoplasmic genes, studies of segregation from heteroplasmons were carried out as previously described (Belcour \& Begel, 1977). Briefly, a CAP-resistant mycelium grown on a permeable paper disc laid on solid CAP-free medium was surrounded by a culture of an $(A) s$ CAP-sensitive mycelium. After anastomoses had formed between the two mycelia, the disc was transferred to CAP-containing medium, on which the growth of the external mycelium ceased. Some days later, growth resumed from discrete points at the outer edge of the culture. In most cases, mycelium taken from these growing sectors contained only the nucleus from the external CAP-sensitive strain but could contain either only CAP-resistant mitochondria or a mixed population of the two types of mitochondria. These latter types, which constituted the heteroplasmons, were selected then purified towards both $c a p^{r} I$ and $c a p^{8} I$ homoplasmons by growing them until they reached a few $\mathrm{cm}$ in length on either CAP-containing medium or CAP-free medium.

\section{RESULTS}

\section{Effect of the mitochondrial cap I mutation on life-span}

Table 1 shows some representative results of measurements of the mean life-spans of $A, s$ and hybrid $(A) s$ strains (see Methods). These results agree with those obtained by others (Marcou, 1961; Smith \& Rubinstein, 1973a). Firstly, the life-span of cultures of the $A$ strain was less than that of cultures of the $s$ strain. Secondly, there were no clear differences between the life-spans of $m t+$ and $m t-$ cultures of the $A$ strain, but for $s$ and $(A) s$ strains, the life-spans of $m t-$ cultures were shorter than those of $m t+$ cultures. Thirdly, cultures of the $(A) s m t-$ strain showed about the same life-span as cultures of the $A m t-$ strain. These results confirmed both a cytoplasmic control of the life-span in $A \times s$ crosses and a strong effect of the $m t+$ gene (or a linked gene) on the life-span of the $s$ strain. However, our numerical values were somewhat different from those previously published; this is partly due to differences in culture conditions, especially the high temperature used here, as shown by comparison of the life-spans of cultures at 26 and $30^{\circ} \mathrm{C}$ (Table 1).

Table 2 shows the life-spans of mycelia carrying the $\operatorname{cap}^{r} I$ mutation. This mitochondrial chloramphenicol-resistant mutation, whose phenotypic properties have been described previously (Belcour \& Begel, 1977), was isolated from the $s m t-$ strain 74-7 (see Table 2 for its life-span). The capr I strains 81 and 82 were isolated after six generations of back-crosses 
Table 1. Life-spans of wild-type $A$ and strains and of hybrid $(A)$ s strains

Measurements were made in tubes on solid corn-meal medium as indicated in Methods. Mycelia

\begin{tabular}{|c|c|c|c|c|c|}
\hline Cytoplasm & Nucleus & Mating type & No. of cultures & $\begin{array}{l}\text { Mean life-span } \\
(\mathrm{cm})\end{array}$ & $\begin{array}{l}\text { Standard } \\
\text { deviation }\end{array}$ \\
\hline$A$ & $A$ & + & $\begin{array}{l}14 \\
12\end{array}$ & $\begin{array}{l}8 \cdot 8 \\
9 \cdot 9\end{array}$ & $\begin{array}{l}0.5 \\
0.8\end{array}$ \\
\hline$A$ & $A$ & - & $\begin{array}{l}18 \\
18\end{array}$ & $\begin{array}{l}10 \cdot 0 \\
10 \cdot 6\end{array}$ & $\begin{array}{l}0 \cdot 8 \\
1 \cdot 5\end{array}$ \\
\hline$A$ & $s$ & + & $\begin{array}{l}21 \\
16\end{array}$ & $\begin{array}{l}37 \cdot 2 \\
30 \cdot 6\end{array}$ & $\begin{array}{l}5 \cdot 2 \\
4 \cdot 9\end{array}$ \\
\hline$A$ & $s$ & - & $\begin{array}{l}68 \\
31\end{array}$ & $\begin{array}{r}10 \cdot 9 \\
9 \cdot 7\end{array}$ & $\begin{array}{l}0 \cdot 5 \\
0 \cdot 4\end{array}$ \\
\hline$s$ & $s$ & + & $\begin{array}{l}19 \\
10\end{array}$ & $\begin{array}{l}31 \cdot 0 \\
87 \cdot 6\end{array}$ & $\begin{array}{r}4 \cdot 0 \\
21 \cdot 5\end{array}$ \\
\hline$s$ & $s$ & - & $\begin{array}{l}52 \\
20 \\
20^{*}\end{array}$ & $\begin{array}{l}18 \cdot 6 \\
15 \cdot 7 \\
35 \cdot 4\end{array}$ & $\begin{array}{l}1.6 \\
1.0 \\
1.9\end{array}$ \\
\hline
\end{tabular}

Table 2. Life-spans of cap I strains and of isonuclear cap ${ }^{\mathrm{s}}$ I strains

All strains in this table have the $s$ nucleus and the $s$ cytoplasm. Life-spans of cap $I$ strains could not be measured precisely (see Methods) and only an underestimation of the mean life-span is given: > signifies that the mean life-span was calculated from both senescent cultures and cultures still growing and/or cultures arrested before senescence; $\gg$ signifies that all cultures were still growing when the experiment was stopped.

\begin{tabular}{|c|c|c|c|}
\hline $\begin{array}{l}\text { Strain } \\
\text { (genotype and ref. no.) }\end{array}$ & $\begin{array}{l}\text { No. of } \\
\text { cultures }\end{array}$ & $\begin{array}{l}\text { Mean life-span } \\
(\mathrm{cm})\end{array}$ & $\begin{array}{l}\text { Standard } \\
\text { deviation }\end{array}$ \\
\hline $\begin{array}{lc}\text { cap }^{\mathrm{s} I m t-} & (74-7) \\
\text { cap }^{\mathrm{s} I m t-} & (78-3) \\
\text { cap }^{\mathrm{s} I m t-} \mathrm{sp37}(74-13) \\
\text { cap }^{\mathrm{s} I m t+} \operatorname{sp} 37(74-14)\end{array}$ & $\begin{array}{l}20 \\
13 \\
10 \\
11\end{array}$ & $\begin{array}{l}17 \cdot 9 \\
18 \cdot 0 \\
15 \cdot 9 \\
31 \cdot 2\end{array}$ & $\begin{array}{l}1 \cdot 4 \\
1 \cdot 3 \\
1 \cdot 2 \\
4 \cdot 1\end{array}$ \\
\hline 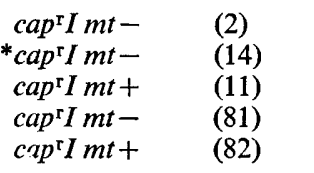 & $\begin{array}{l}28 \\
20 \\
19 \\
12 \\
12\end{array}$ & $\begin{array}{l}>171 \\
>500 \\
>140 \\
>66 \\
>66\end{array}$ & $\begin{array}{l}- \\
\overline{-} \\
-\end{array}$ \\
\hline $\begin{array}{l}c a p^{\mathrm{r} I} m t-s p 37(9) \\
c a p^{\mathrm{r} I} m t+s p 37(1) \\
c a p^{\mathrm{I} I} m t+s p 37(14)\end{array}$ & $\begin{array}{l}20 \\
32 \\
10\end{array}$ & $\begin{array}{l}>240 \\
>150 \\
>120\end{array}$ & E \\
\hline
\end{tabular}

* From this experiment, started in July 1975, 2 cultures are still growing, 5 others were mutated to 'incolore' and 13 others became senescent between 130 and $670 \mathrm{~cm}$ of growth.

of the capr $I$ mutant (female parent) with a $\operatorname{cap}^{s} I$ strain (male parent). The $\operatorname{cap}^{\mathrm{r} I}$ strains 2 , 14 and 11 were isolated from the first, second and fourth generations of these back-crosses, respectively. We also introduced an additional nuclear marker, $s p 37$, into strains carrying the cap $I$ mutation. The life-spans of $c a p^{\mathrm{r}} I s p 37$ and isonuclear cap ${ }^{8} I s p 37$ mycelia are included in Table 2.

Although the life-spans of the cap $I$ cultures could not always be measured exactly (see Methods), they were at least five times greater than those of isonuclear $\operatorname{cap}^{8} I$ cultures. This property was maternally inherited, like the character of CAP resistance, in the crosses by spermatization, i.e. in crosses carried out without any cytoplasmic mixing between the two parents (see Methods).

Cytoplasmic analysis of the $\operatorname{cap}^{\mathrm{r}} I$ strain was carried out by studying the segregation of 


\section{Table 3. Analysis of heteroplasmons}

After cytoplasmic mixing of the two parental homoplasmons, heteroplasmons containing the $m t-$ nucleus and the two mitochondrial markers were isolated and then purified towards both $\operatorname{cap}^{\mathrm{r}} \boldsymbol{I}$ and $c a p s I$ homoplasmons. The life-spans of purified homoplasmons were measured in the same time and under identical conditions as for the parental homoplasmons (see Methods). The $\operatorname{cap}^{\mathrm{r} I}$ parental homoplasmons contained cytoplasm from the wild-type $s$ strain, while cap ${ }^{8} I$ parental homoplasmons contained the cytoplasm of the wild-type $A$ strain.

Expt

o. Genotype of mycelium

1 Parental homoplasmons cap I sp37 $m t+$ cap $^{8} I s p 37^{+} m t-$

Purified homoplasmons $\operatorname{cap}^{\mathrm{r}} I \mathrm{sp} 37^{+} m t-$ cap 8 I sp $37^{+} m t-$

2 Parental homoplasmons cap I sp $37^{+} m t+$ cap ${ }^{8}$ sp $37 \mathrm{mt}-$

Purified homoplasmons cap I sp37 $m t-$ cap $^{8}$ sp37 $m t-$

$\begin{array}{cc}\text { Cytoplasm } & \begin{array}{c}\text { No. of } \\ \text { cultures }\end{array} \\ s & 17 \\ A & 18 \\ & 18 \\ & 18 \\ & \\ S & 19 \\ A & 18 \\ & 17 \\ & 24\end{array}$

* For significance of $>$, see Table 2 .

heteroplasmic mycelia. By a method previously described (Belcour \& Begel, 1977) and briefly referred to in Methods, we obtained, after anastomoses between a short-lived (A) $s m t-$ mycelium and a long-lived $\operatorname{cap}^{\mathrm{r}} I m t+$ mycelium, heteroplasmons containing only the $m t-$ nucleus from the short-lived $(A) s$ strain but containing a mixed population of $c a p^{\mathrm{r}} I$ and $\operatorname{cap}^{\mathrm{s}} I$ mitochondria. From these heteroplasmons, $c a p^{\mathrm{r}} I$ and $\operatorname{cap}^{\mathrm{s}} I$ homoplasmons were isolated by growth on either CAP-containing medium or CAP-free medium. The lifespans of these purified homoplasmons were then measured on CAP-free medium along with those of the parental homoplasmons. From the results presented in Table 3, it seems that the $\operatorname{cap}^{\mathrm{r}} I$ mitochondrial mutation greatly increased the life-span, since purified homoplasmons containing the same nucleus showed very different life-spans according to whether they carried the $c a p^{\mathrm{r}} I$ or the $c a p^{8} I$ allele. However, in the first experiment, we found a $c^{\mathrm{s}} \boldsymbol{I}$ purified homoplasmon that was shorter-lived than any other $c^{x}{ }^{\mathrm{I}} I$ strain so far measured (see Table 2 for comparison). Conversely, in the second experiment, we found a $c^{8} p^{8} I$ homoplasmon that was longer-lived than the parental isonuclear homoplasmon. From the results in Table 3, we conclude that there is a cytoplasmic control of the life-span in which the $c a p^{r} I$ mitochondrial gene plays an important role, but this cannot account entirely for the observed results. Similar conclusions were reached by Raynal (1978) through a different experimental approach.

\section{Effects of CAP, EB and $C H X$ on life-span}

The effects of CAP and EB, which are considered to act on mitochondrial protein synthesis and on mitochondrial DNA replication and transcription, respectively, and of CHX, which is considered to act on cytoplasmic protein synthesis, were studied. Table 4 shows the lifespans of different strains in the presence and absence of the drugs used at concentrations which only slightly inhibited the elongation rate of the mycelium. CAP and EB greatly increased the life-spans of all strains studied, whereas CHX decreased the life-span at both 30 and $26^{\circ} \mathrm{C}$. In the case of $\mathrm{CHX}$ we investigated the possibility that the observed early arrest of growth was not due to senescence but either to a delayed death induced by the drug 
Table 4. Effect of $C A P, E B$ and $C H X$ on the life-spans of $A, A(s)$ and strains

In each experiment, measurements were made on drug-free medium (control) and using one or two different concentrations of the drug.

\begin{tabular}{|c|c|c|c|c|c|c|c|c|}
\hline & Strain & & & & & & & \\
\hline Cytoplasm & Nucleus & $\begin{array}{c}\text { Mating } \\
\text { type }\end{array}$ & $\underset{\left(\mu \mathrm{g} \mathrm{ml}^{-1}\right)}{\text { Drug }}$ & $\begin{array}{l}\text { Linear } \\
\text { growth } \\
\text { rate }(\%)^{*}\end{array}$ & $\begin{array}{l}\text { No. of } \\
\text { cultures }\end{array}$ & $\begin{array}{c}\text { Mean } \\
\text { life-span } \\
(\mathrm{cm}) \dagger\end{array}$ & $\begin{array}{l}\text { Standard } \\
\text { deviation }\end{array}$ & Line \\
\hline$A$ & $A$ & $m t+$ & - & 100 & 6 & $8 \cdot 3$ & $0 \cdot 3$ & 1 \\
\hline & & & EB (6) & - & 10 & $>59 \cdot 4$ & 一 & 2 \\
\hline$A$ & $A$ & $m t-$ & 一 & 100 & 12 & 8.9 & 0.9 & 3 \\
\hline & & & CAP (600) & 86 & 6 & $23 \cdot 5$ & $3 \cdot 1$ & 4 \\
\hline & & & - & 100 & 6 & $10 \cdot 5$ & $0 \cdot 3$ & 5 \\
\hline & & & EB (6) & - & 11 & $>66 \cdot 0$ & - & 6 \\
\hline$A$ & $s$ & $m t-$ & - & 100 & 10 & $12 \cdot 2$ & 0.5 & 7 \\
\hline & & & CAP (1000) & 76 & 8 & $22 \cdot 2$ & $2 \cdot 6$ & 8 \\
\hline & & & CAP (2000) & 60 & 9 & $20 \cdot 7$ & $1 \cdot 1$ & 9 \\
\hline & & & 一 & 100 & 31 & $9 \cdot 7$ & 0.4 & 10 \\
\hline & & & CAP (400) & 92 & 10 & $12 \cdot 2$ & $0 \cdot 5$ & 11 \\
\hline & & & CAP (600) & 85 & 29 & $32 \cdot 8$ & $3 \cdot 4$ & 12 \\
\hline & & & $-\ddagger$ & 100 & 21 & $9 \cdot 9$ & 0.4 & 13 \\
\hline & & & 一 & 100 & 28 & $11 \cdot 7$ & $0 \cdot 4$ & 14 \\
\hline & & & CAP§ (600) & 89 & 6 & $64 \cdot 0$ & $11 \cdot 7$ & 15 \\
\hline & & & - & 100 & 10 & $9 \cdot 2$ & $0 \cdot 2$ & 16 \\
\hline & & & EB (6) & 93 & 10 & $>88.0$ & - & 17 \\
\hline & & & EB (30) & 67 & 9 & $>53 \cdot 0$ & - & 18 \\
\hline & & & - & 100 & 22 & $11 \cdot 3$ & $0 \cdot 6$ & 19 \\
\hline & & & CHX (1) & 86 & 9 & $7 \cdot 2$ & 0.5 & 20 \\
\hline & & & CHX (2) & 74 & 23 & $5 \cdot 1$ & $0 \cdot 1$ & 21 \\
\hline & & & - & 100 & 12 & $9 \cdot 5$ & 0.4 & 22 \\
\hline & & & CHX (1.5) & 81 & 12 & $4 \cdot 3$ & 0.2 & 23 \\
\hline & & & CHX $(2 \cdot 5)$ & 65 & 11 & $3 \cdot 5$ & $0 \cdot 2$ & 24 \\
\hline & & & $-\|$ & 100 & 10 & $20 \cdot 0$ & $0 \cdot 8$ & 25 \\
\hline & & & $\mathrm{CHX} \|(2)$ & 75 & 12 & $10 \cdot 4$ & $0 \cdot 3$ & 26 \\
\hline$A$ & $s$ & $m t+$ & - & 100 & 8 & $31 \cdot 5$ & $2 \cdot 9$ & 27 \\
\hline & & & $\mathrm{CHX}$ (1) & 82 & 9 & $7 \cdot 8$ & $1 \cdot 1$ & 28 \\
\hline & & & - & 100 & 10 & $>52 \cdot 4$ & - & 29 \\
\hline & & & CHX (2) & 77 & 8 & $10 \cdot 3$ & $0 \cdot 5$ & 30 \\
\hline$s$ & $s$ & $m t-$ & 一 & 100 & 18 & $17 \cdot 9$ & $0 \cdot 6$ & 31 \\
\hline & & & CAP\$ (600) & 84 & 6 & $54 \cdot 9$ & $14 \cdot 7$ & 32 \\
\hline & & & $-\ddagger$ & 100 & 10 & $18 \cdot 5$ & $1 \cdot 0$ & 33 \\
\hline & & & - & 100 & 6 & $17 \cdot 9$ & $1 \cdot 3$ & 34 \\
\hline & & & EB (6) & 90 & 11 & $>66 \cdot 0$ & 一 & 35 \\
\hline & & & - & 100 & 15 & $19 \cdot 2$ & $1 \cdot 3$ & 36 \\
\hline & & & CHX (1) & 83 & 19 & $9 \cdot 4$ & 0.7 & 37 \\
\hline & & & CHX (2) & 76 & 13 & $9 \cdot 4$ & 0.5 & 38 \\
\hline
\end{tabular}

* Elongation rate of the mycelium on drug-containing medium expressed as a percentage of the elongation rate on drug-free medium.

$\dagger$ For significance of $>$, see Table 2 .

$\ddagger$ Life-span on CAP-free medium after growth of mycelium on CAP-containing medium: in each experiment, cultures were initiated with implants taken from five different mycelia after they had grown for $20 \mathrm{~cm}$ on CAP-containing medium.

$\S$ CAP from Serva; in all other experiments CAP was from Roussel UCLAF.

\| Cultures were grown at $26^{\circ} \mathrm{C}$. 
or to a delayed inhibition of growth. Implants taken from 1 to $2 \mathrm{~cm}$ behind the arrested edge of the cultures and transferred to drug-free medium grew to a small extent and then stopped, displaying all the morphological symptoms of senescence.

The effects produced by CAP and EB could result from two different mechanisms. The drugs could either decrease the probability of commitment to senescence (i.e. the appearance of the 'senescent cytoplasmic factor') or increase the incubation period (i.e. the period of growth needed for complete invasion of the mycelium by the cytoplasmic factor). We investigated these possibilities by transferring mycelium after a long period of growth on drug-containing medium to drug-free medium. After $20 \mathrm{~cm}$ (or more) growth on medium containing CAP $\left(600 \mu \mathrm{g} \mathrm{ml}^{-1}\right), 21$ implants from five different cultures of the $(A) s m t-$ strain were transferred to CAP-free medium. The resulting cultures showed exactly the same life-spans as the initial cultures of the $(A) s m t$ - strain on CAP-free medium (Table 4, lines 10, 12 and 13). The same result was obtained for an $s m t-$ strain (Table 4, lines 31 , 32 and 33). Thus, after $20 \mathrm{~cm}$ growth on CAP-containing medium, i.e. longer than the mean life-span of the strains used, none of the cultures was yet committed to senescence. Therefore, CAP prevented the commitment to senescence in these cultures.

Similar results were also found after growth on EB-containing medium (although not so regularly). In this case, two types of results were obtained: either the mycelia transferred to EB-free medium after a long growth period on EB-containing medium showed the characteristic life-span of the strain or they displayed a much shorter life-span, while they could continue for a long time on EB-containing medium (results not shown). In the latter case, we conclude that EB acted by delaying the complete invasion of the mycelium by the senescent cytoplasmic factor.

Thus, CAP seems to act mainly by decreasing the probability of commitment to senescence, although an effect on the incubation period cannot be excluded (precise measurements of the incubation period on CAP-containing medium have not been made). EB seems to act both by decreasing the commitment probability and by increasing the incubation period.

\section{Effect of $C A P$ and $E B$ on senescent cultures}

The effect of CAP and EB on senescent cultures was tested by transferring senescent mycelia grown on normal medium to drug-containing medium. In some cases, this allowed senescent mycelia to continue growing for a longer period than in control experiments in which similar mycelia were transferred to normal medium. Table 5 shows that in all the experiments mycelia grew on drug-free medium for a shorter time than the mean life-span of the corresponding strain. This indicated that mycelia were indeed committed to senescence. On drug-containing medium, very different results were obtained, depending on the drug used and also on how far from the arrested edge of the senescent culture the transferred implants were taken. While EB was efficient even on very senescent mycelium and allowed growth from a high proportion of implants taken very near the arrested edges of senescent cultures, CAP seemed to enable senescent mycelia to grow only during the first step of the development of senescence, i.e. when implants were taken far enough (about $4 \mathrm{~cm}$ or more) from the arrested edges of the senescent cultures.

On drug-containing medium we observed, in most cases, two types of growth behaviour: either cultures stopped after a few $\mathrm{cm}$ or they grew for a long time. In Table 5, cultures have been classified into two groups depending on whether they grew less or more than $10 \mathrm{~cm}$. Some of the latter group were further analysed by taking implants after 20 or $30 \mathrm{~cm}$ growth on drug-containing medium and transferring them, again in parallel, to drug-free and drug-containing medium. The results are shown in Table 6. Four different types of behaviour were observed. (1) Senescence quickly appeared after transfer to either drugcontaining medium or drug-free medium (Table 6, lines 6 and 7). (2) Mycelia continued to grow for a long time on drug-containing medium but showed a shorter life-span on drugfree medium than did the parental strain (about $18 \mathrm{~cm}$ for strain $s m t-$ and $10 \mathrm{~cm}$ for strain 


\section{Table 5. Effect of CAP and EB on senescent mycelia}

Implants were taken from senescent mycelia at the distance from the arrested edge indicated in column 3 and were transferred to drug-free and drug-containing media. The life-spans measured on drug-free medium indicated the senescent state of the mycelium. The life-spans on drug-containing medium were classified as 'long' or 'short' depending on whether mycelia grew more or less than $10 \mathrm{~cm}$; with only a few exceptions, mycelia either grew only a few $\mathrm{cm}$ or very much more. The life-spans of the strains used are about $9 \mathrm{~cm}$ for $A m t+, 18 \mathrm{~cm}$ for $s m t-$ and $10 \mathrm{~cm}$ for (A)s $m t-$ (see Tables 1 and 4).

\begin{tabular}{|c|c|c|c|c|c|c|c|c|c|c|}
\hline \multirow[b]{2}{*}{$\begin{array}{c}\text { Expt } \\
\text { no. }\end{array}$} & \multirow[b]{2}{*}{ Strain } & \multirow[b]{2}{*}{$\begin{array}{l}\text { Distance } \\
(\mathrm{cm})\end{array}$} & \multicolumn{2}{|c|}{$\begin{array}{c}\text { Drug-free } \\
\text { medium }\end{array}$} & \multicolumn{6}{|c|}{ Drug-containing medium } \\
\hline & & & $\begin{array}{l}\text { No. of } \\
\text { cultures }\end{array}$ & $\begin{array}{c}\text { Growth } \\
(\mathrm{cm})\end{array}$ & $\begin{array}{l}\text { No. of } \\
\text { cultures } \\
\text { (total) }\end{array}$ & $\begin{array}{c}\text { Drug } \\
\left(\mu \mathrm{g} \mathrm{ml}^{-1}\right)\end{array}$ & $\begin{array}{l}\text { No. of } \\
\text { cultures } \\
\text { (short) }\end{array}$ & $\begin{array}{c}\text { Growth } \\
(\mathrm{cm})\end{array}$ & $\begin{array}{c}\text { No. of } \\
\text { cultures } \\
\text { (long) }\end{array}$ & $\begin{array}{c}\text { Growth } \\
\text { (cm) }\end{array}$ \\
\hline 1 & $A m t+$ & $1 \cdot 5$ & 32 & 2 & 20 & EB (20) & 20 & $2 \cdot 5$ & 0 & 一 \\
\hline 2 & $A m t+$ & $1 \cdot 0$ & 14 & 2 & $\begin{array}{r}6 \\
12\end{array}$ & $\begin{array}{l}\text { EB (20) } \\
\text { EB (6) }\end{array}$ & $\begin{array}{l}1 \\
4\end{array}$ & $\begin{array}{l}0.0 \\
4.5\end{array}$ & $\begin{array}{l}5 \\
8\end{array}$ & $>33$ \\
\hline 3 & $A m t+$ & $1 \cdot 0$ & 6 & 2 & $\begin{array}{l}6 \\
6\end{array}$ & $\begin{array}{l}\mathrm{EB}(20) \\
\mathrm{EB}(6)\end{array}$ & $\begin{array}{l}2 \\
2\end{array}$ & $\begin{array}{l}0 \cdot 0^{+} \\
3 \cdot 5\end{array}$ & $\begin{array}{l}4 \\
4\end{array}$ & $\begin{aligned} &> 23 \\
& 12 \cdot 8\end{aligned}$ \\
\hline 4 & $A m t+$ & $1 \cdot 0$ & 6 & 2 & 6 & $\mathrm{~EB}(6)$ & 2 & $6 \cdot 0$ & 4 & $>33$ \\
\hline 5 & $s m t-$ & $1 \cdot 5$ & 40 & 2 & 25 & EB (20) & 0 & - & 25 & $53 *$ \\
\hline 6 & $s m t-$ & $1 \cdot 0$ & 14 & 3 & $\begin{array}{l}7 \\
7\end{array}$ & $\begin{array}{l}\text { EB (8) } \\
\text { EB (32) }\end{array}$ & $\begin{array}{l}7 \\
4\end{array}$ & $\begin{array}{l}3 \cdot 2 \\
0 \cdot 0^{+}\end{array}$ & $\begin{array}{l}0 \\
3\end{array}$ & $>\overline{56^{*}}$ \\
\hline 7 & $s m t-$ & $1 \cdot 0$ & 12 & 3 & 14 & $\mathrm{~EB}(20)$ & 5 & $4 \cdot 9$ & 9 & 57 \\
\hline 8 & $s m t-$ & $1 \cdot 0$ & 12 & 3 & 6 & $\mathrm{~EB}(6)$ & 3 & $6 \cdot 2$ & 3 & 50 \\
\hline 9 & $s m t-$ & $1 \cdot 0$ & 12 & 3 & 6 & EB (6) & 3 & $6 \cdot 8$ & 3 & $>32$ \\
\hline 10 & $s m t-$ & $1 \cdot 0$ & 12 & 3 & 6 & EB (6) & 5 & $2 \cdot 4$ & 1 & 33 \\
\hline 11 & $s m t-$ & $2 \cdot 0$ & 24 & $2 \cdot 1$ & 12 & CAP (500) & 12 & $0 \cdot 8$ & 0 & - \\
\hline & & & & & 12 & CAP (1000) & 12 & $1 \cdot 5$ & 0 & - \\
\hline & & & & & 12 & CAP (2000) & 12 & $2 \cdot 5$ & 0 & - \\
\hline 12 & $s m t-$ & $3 \cdot 0$ & 12 & $3 \cdot 2$ & 12 & CAP $(600)$ & 12 & $3 \cdot 7$ & 0 & 一 \\
\hline 13 & $(A) s m t-$ & $3 \cdot 0$ & 16 & $2 \cdot 9$ & 16 & CAP (600) & 16 & $3 \cdot 2$ & 0 & - \\
\hline 14 & (A)s $m t-$ & $4 \cdot 0$ & 42 & $3 \cdot 7$ & 28 & CAP (600) & 27 & 38 & 1 & $>66$ \\
\hline 15 & (A)s $m t-$ & $5 \cdot 0$ & 54 & $3 \cdot 8$ & 54 & CAP (600) & 50 & $5 \cdot 3$ & 4 & $13 \cdot 1$ \\
\hline 16 & (A)s $m t-$ & $5 \cdot 0$ & 4 & $4 \cdot 8$ & 6 & CAP (600) & 1 & $9 \cdot 0$ & 5 & $>39^{*}$ \\
\hline 17 & (A)s $m t-$ & $5 \cdot 0$ & 54 & $4 \cdot 8$ & 92 & CAP (600) & 58 & $6 \cdot 1$ & 34 & $>23.7^{*}$ \\
\hline 18 & $(A) s m t-$ & $6 \cdot 0$ & 18 & $6 \cdot 5$ & 20 & CAP (600) & 2 & $9 \cdot 0$ & 18 & $>53.4$ \\
\hline
\end{tabular}

(A)s $m t-$; Tables 1 and 4), as clearly shown in Table 6, lines 4 and 5. (3) Mycelia continued to grow on drug-containing medium and showed about the same life-span as the original young strain on drug free-medium (Table 6, lines 3, 9, 12, 13, 15 and most probably lines 1, 2, 8 and 14). (4) Mycelia appeared to show a greater life-span on drug-free medium than did the original young strain (Table 6, lines 11 and, perhaps, 10).

In cases (1) and (2), the mycelium was committed to senescence before transfer, but in case (1) senescence was expressed on both types of media whereas in case (2) it was expressed only on drug-free medium. In this case, as we saw previously, EB was able to delay the expression of senescence. This effect was never clearly seen with CAP treatment. In case (3), mycelia had returned to a young state after transfer. This was the most frequent case and is interpreted as a reversion from senescence induced by the action of EB and CAP. In case (4), mycelia showed a greater life-span than the original young strain. This could be interpreted as a change in life-span induced by the treatment. Such strains are now under investigation to determine whether the apparent change in life-span resulted from a genetic change.

\section{DISCUSSION}

The results presented here clearly demonstrate that the life-spans of cultures of Podospora anserina are greatly increased by the action of the mitochondrial mutation cap $^{\mathrm{r}} I$ or by growth in the presence of CAP or EB which are known to be specific inhibitors of mito- 


\section{Table 6. Effect of CAP and EB on senescent mycelia - further experiments}

Mycelia derived from senescent cultures and having grown to at least $20 \mathrm{~cm}$ on CAP- or EBcontaining medium were examined further to determine whether they still contained the senescent factor. Implants were taken and transferred in parallel to normal and drug containing medium. The table gives the life spans of these transferred cultures from the time of transfer.

\begin{tabular}{|c|c|c|c|c|c|c|c|}
\hline \multirow[b]{2}{*}{ Mycelium } & \multicolumn{3}{|c|}{ Drug containing medium } & \multicolumn{3}{|c|}{ Drug-free medium } & \\
\hline & $\begin{array}{c}\text { Drug } \\
\left(\mu \mathrm{g} \mathrm{ml}^{-1}\right)\end{array}$ & $\begin{array}{l}\text { No. of } \\
\text { cultures }\end{array}$ & $\begin{array}{l}\text { Mean } \\
\text { life.span } \\
(\mathrm{cm})\end{array}$ & $\begin{array}{l}\text { No. of } \\
\text { cultures }\end{array}$ & $\begin{array}{l}\text { Mean } \\
\text { life-span } \\
\quad(\mathrm{cm})\end{array}$ & $\begin{array}{l}\text { Standard } \\
\text { deviation }\end{array}$ & Line \\
\hline $\begin{array}{l}s m t-, \text { from expt } 5 \\
\text { Table } 5 \\
\left(\text { EB } 20 \mu \mathrm{g} \mathrm{ml}^{-1}\right)\end{array}$ & $\begin{array}{l}\text { EB }(20) \\
\text { EB (20) } \\
\text { EB }(20)\end{array}$ & $\begin{array}{l}5 \\
5 \\
5\end{array}$ & $\begin{array}{l}>57 \\
>52 \\
>53\end{array}$ & $\begin{array}{l}5 \\
5 \\
5\end{array}$ & $\begin{array}{l}14 \cdot 3 \\
13 \cdot 7 \\
19 \cdot 6\end{array}$ & $\begin{array}{l}1 \cdot 2 \\
0 \cdot 3 \\
2 \cdot 1\end{array}$ & $\begin{array}{l}1 \\
2 \\
3\end{array}$ \\
\hline $\begin{array}{l}s m t-, \text { from expt } 6, \\
\text { Table } 5 \\
\left(\text { EB } 32 \mu \mathrm{g} \mathrm{ml}^{-1}\right)\end{array}$ & $\begin{array}{l}\text { EB (20) } \\
\text { EB (20) } \\
\text { EB (20) }\end{array}$ & $\begin{array}{l}1 \\
1 \\
1\end{array}$ & $\begin{array}{r}>30 \\
>30 \\
5\end{array}$ & $\begin{array}{l}4 \\
4 \\
4\end{array}$ & $\begin{array}{l}8 \cdot 9 \\
8 \cdot 3 \\
1 \cdot 8\end{array}$ & $\begin{array}{l}0 \cdot 8 \\
0 \cdot 4 \\
0 \cdot 3\end{array}$ & $\begin{array}{l}4 \\
5 \\
6\end{array}$ \\
\hline $\begin{array}{l}\text { (A)s } m t-\text {, from expt } 16 \text {, } \\
\text { Table } 5 \\
\left(\text { CAP } 600 \mu \mathrm{g} \mathrm{ml}^{-1} \text { ) }\right.\end{array}$ & $\begin{array}{l}\text { CAP (600) } \\
\text { CAP }(600) \\
\text { CAP }(600) \\
\text { CAP }(600) \\
\text { CAP }(600)\end{array}$ & $\begin{array}{l}1 \\
1 \\
1 \\
1 \\
1\end{array}$ & $\begin{array}{r}5 \\
>53 \\
>53 \\
>53 \\
>53\end{array}$ & $\begin{array}{l}6 \\
4 \\
6 \\
6 \\
6\end{array}$ & $\begin{array}{r}2 \cdot 5 \\
8 \cdot 6 \\
11 \cdot 3 \\
19 \cdot 7 \\
23 \cdot 7\end{array}$ & $\begin{array}{l}0 \cdot 2 \\
0 \cdot 5 \\
0 \cdot 7 \\
2 \cdot 3 \\
2 \cdot 3\end{array}$ & $\begin{array}{r}7 \\
8 \\
9 \\
10 \\
11\end{array}$ \\
\hline $\begin{array}{l}\text { (A)s } m t-\text {, from expt } 17 \text {, } \\
\text { Table } 5 \\
\left(\text { CAP } 600 \mu \mathrm{g} \mathrm{ml}^{-1}\right)\end{array}$ & $\begin{array}{l}\text { CAP }(600) \\
\text { CAP }(600) \\
\text { CAP }(600) \\
\text { CAP }(600)\end{array}$ & $\begin{array}{l}1 \\
1 \\
1 \\
1\end{array}$ & $\begin{array}{l}>33 \\
>33 \\
>33 \\
>33\end{array}$ & $\begin{array}{l}6 \\
6 \\
6 \\
6\end{array}$ & $\begin{array}{r}14 \cdot 1 \\
12 \cdot 8 \\
8 \cdot 5 \\
13 \cdot 0\end{array}$ & $\begin{array}{l}1 \cdot 2 \\
0.7 \\
0.5 \\
0.7\end{array}$ & $\begin{array}{l}12 \\
13 \\
14 \\
15\end{array}$ \\
\hline
\end{tabular}

chondrial functions. In contrast, CHX, which inhibits cytoplasmic protein synthesis, was shown to decrease the life-span. These results were established from repeated experiments carried out on $A, s$ and $(A) s$ strains (Table 4) using concentrations of drugs that were just sufficient to cause a slight decrease in the elongation rate of the mycelia. Furthermore, EB and CAP could rejuvenate senescent mycelia. Long-term cold treatment has also been shown to rejuvenate senescent mycelia (Marcou, 1954, 1961). Treatment with CAP or EB seems to constitute an efficient and easier means of obtaining the same result. EB, in particular, can act on mycelium that is far advanced in the process of senescence.

Our results on the effect of drugs on young and senescent mycelia should be compared with those reported elsewhere. Tudzynski \& Esser $(1977,1979)$ observed a lengthening effect of EB treatment used at about the same concentrations as in the present work but found no effect with CAP or CHX. However, their results with CAP do not contradict our results as they used a concentration of $320 \mu \mathrm{g} \mathrm{ml}^{-1}$ or less and we observed only a weak (if significant) effect on the life-span when CAP was used at $400 \mu \mathrm{g} \mathrm{ml}^{-1}$ (Table 4 , lines 10 and 11). For CHX treatment, Holliday (1969) and Tudzynski \& Esser (1977) used about the same concentrations as we did but did not observe any shortening effect on mycelia of strain $s$. This discrepancy was first assumed to be related to the higher temperature $\left(30^{\circ} \mathrm{C}\right)$ used in our experiments. However, we obtained similar results when the $\mathrm{CHX}$ treatment was carried out at $26^{\circ} \mathrm{C}$ (Table 4 , lines 25 and 26 ).

Smith \& Rubinstein (1973a) investigated the action of several drugs on senescent mycelia and demonstrated that treatment with cyanide and $\mathrm{CHX}$ significantly increased the life-span of senescent mycelia, while they found no such effect with CAP. This last point does not disagree with our results, since we showed that the 'curing' effect of CAP was not observed in all cases (Table 5) and, furthermore, we used much longer periods of treatment than did Smith \& Rubinstein (4 d). It is difficult to explain how CHX, which Tudzynski \& Esser found to have no effect and which showed a shortening effect on our experiments, can 'cure' senescent mycelia; it must be noted, however, that Smith \& Rubinstein used CHX at a concentration at least six times greater than we did. 
In spite of the remaining discrepancy in the effect of $\mathrm{CHX}$, we consider that our conclusions concerning the effects of drugs are valid under the experimental conditions used, since they are based on reproducible results of repeated experiments made on mycelia of three different strains (Table 4).

Possible mode of action of CAP and EB. CAP and EB acted in somewhat different ways on the life-span of young mycelia and in the rejuvenation of senescent mycelia. EB had a greater effect on both. Also, EB sometimes allowed the growth of senescent mycelia without curing, i.e. mycelia continued to grow on EB-containing medium but displayed senescence on transfer to EB-free medium. In contrast, CAP could only rejuvenate senescent mycelia if they were not too advanced in the senescence process; otherwise, senescence was expressed in the presence of CAP as well as in its absence.

Before discussing the possible meaning of these results, we must exclude a trivial interpretation of the lengthening effect of drugs (and of the cap $I$ mutation as well) which could be that any condition reducing the growth rate would result in an increased life-span. Such an interpretation could not explain the effect of either CHX (which then would be the only meaningful result) or that of other drugs, such as dimethylformamide or 3-(3,4-dichlorophenyl)-1,1-dimethylurea, which did not increase the life-span, but decreased the elongation rate at concentrations of 1000 and $40 \mu \mathrm{g} \mathrm{ml}^{-1}$, respectively (results not shown).

In the three situations in which life-span is prolonged, cytochrome spectra recorded on whole mycelium were deficient in the cytochrome $a a_{3}$ peak $(608 \mathrm{~nm})$. This was previously described for the cap ${ }^{\mathrm{r} I}$ mutant and CAP-treated $\operatorname{cap}^{\mathrm{s}} I$ mycelium (Belcour \& Begel, 1977). In the case of EB treatment we showed a more than twofold decrease in cytochrome $a a_{3}$ content when mycelium was grown in a medium containing as little as $1 \mu \mathrm{g} \mathrm{EB} \mathrm{ml}^{-1}$ (unpublished results). Under such conditions (slightly reduced growth rate and complete or near complete lack of cytochrome $a a_{3}$ peak) it can be assumed that a cyanide-insensitive respiratory chain, as has been shown to exist in many eukaryotic organisms (Degn et al., 1978) and is believed to exist in Podospora (Belcour et al., 1978), is induced. In the closely related fungus Neurospora, Edwards \& Rosenberg (1976) demonstrated that treatment of mycelium with CAP or EB resulted in the induction of cyanide-insensitive respiration. Furthermore, they showed that $\mathrm{CHX}$ added at a concentration as low as $0.5 \mu \mathrm{g} \mathrm{ml}^{-1}$ completely prevented the appearance of cyanide-insensitive respiration in the cultures. From this we can assume that prolongation of life-span is correlated with a full functioning of the alternative respiratory pathway while reduction in life-span (in the case of CHX treatment) is correlated with a complete block of this pathway. Such an interpretation is now under investigation by testing the effect of some additional drugs (especially salicylhydroxamic acid, a specific inhibitor of the cyanide-insensitive respiratory chain) on the life-span.

The mitochondrial control of life-span and senescence. The study of heteroplasmons resulting from mixed cytoplasms of an $(A) s$ and of a $c^{a}{ }^{r} I$ strain confirmed the lengthening effect of the mitochondrial mutation $c^{2} p^{r} I$, but also demonstrated that the two parental strains differed in another cytoplasmic factor acting on the life-span. Smith \& Rubenstein $(1973 a)$ showed that the cytoplasm of wild-type strain $A$ contained a factor for short life-span while wild-type strain $s$ contained a factor for long life-span. The results we obtained could be easily understood by assuming a reassortment between mitochondrial cap ${ }^{\mathrm{r}} / \mathrm{cap}^{*}$ alleles and the cytoplasmic factor identified by Smith \& Rubenstein. By studying further mycelia carrying the mitochondrial $\operatorname{cap}^{\mathrm{r}} I$ marker and displaying a life-span intermediate between those of the parental $c a p^{r} I$ and $c a p^{s} I$ strains, Raynal (1978) demonstrated that they contained the cytoplasmic factor for short life-span carried by the $A$ strain. Two possible explanations can be considered: either the two cytoplasmic factors are carried by the mitochondrial DNA and the newly observed associations resulted from mitochondrial recombination, shown to occur frequently in Podospora anserina (Belcour \& Begel, 1977), or one is carried by mitochondrial DNA $\left(c a p^{r} I\right)$ and the other is a non-mitochondrial cytoplasmic factor whose molecular nature and cellular localization remain to be discovered. We favour 
the former hypothesis, because it is the simplest and also because it has previously been shown that mitochondrial DNAs from geographical races $A$ and $s$ give different restriction patterns when digested by endonuclease EcoRI (Cummings et al., 1979a).

The existence of relationships between senescence and mitochondrial genes and functions had been suggested by several observations. (1) In the progeny of crosses between two mitochondrial mutants spgl and spg2, a small percentage of mycelia displaying premature senescence were found. Genetical and physiological studies of these mycelia led us to propose a mitochondrial origin for senescence in Podospora anserina (Belcour \& Begel, 1978). (2) Another mitochondrial mutant, mitB (Belcour et al., 1978), was selected as a growing sector that appeared at the arrested edge of a senescent culture of a wild-type $s$ strain. To our knowledge, this is the first case of the spontaneous appearance of a growing mycelium after the onset of senescence; the fact that it resulted from a mitochondrial mutation seemed significant. (3) Cytochrome spectra for both senescent mycelium of Podospora anserina and of a similar cytoplasmic variant of Aspergillus were strongly deficient in cytochrome $a a_{3}$, most probably due to impaired mitochondrial protein synthesis (Belcour \& Begel, 1978; Cummings et al., 1979b; Handley \& Caten, 1973; Caten \& Handley, 1978).

The results presented here provide additional support for a strong correlation between senescence and mitochondrial physiology. Examination of mitochondrial DNA has recently revealed differences in density, size and EcoRI digestion pattern between mitochondrial DNA extracted from young and senescent cultures (Cummings et al., 1979b).

The authors thank Marie-Rose Dulchain for her help in preparing cultures. They are also indebted to Dr Janine Beisson and Eric Petrochilo for their help in completion of the manuscript.

\section{REFERENCES}

Belcour, L. \& Begel, O. (1977). Mitochondrial genes in Podospora anserina. Recombination and linkage. Molecular and General Genetics 153, 11-21.

Belcour, L. \& Begel, O. (1978). Lethal mitochondrial genotypes in Podospora anserina. A model for senescence. Molecular and General Genetics 163, 113-123.

Belcour, L., Begel, O., Duchiron, F. \& Lecompte, P. (1978). Four mitochondrial loci in Podospora anserina. Neurospora Newsletter 25, 26-27.

Caten, C. E. \& Handley, L. (1978). Vegetative death syndrome in Aspergillus glaucus. Bulletin of the British Mycological Society 12, 114.

Cummings, D. J., Belcour, L. \& Grandchamp, C. (1978). Etude au microscope électronique du DNA mitochondrial de Podospora anserina et présence d'une série de molécules circulaires de DNA dans des cultures sénescentes. Comptes rendus hebdomadaire des séances de l'Académie des sciences $287,157-160$.

Cummings, D. J., Belcour, L. \& Grandchamp, C. (1979a). Mitochondrial DNA from Podospora anserina I. Isolation and characterization. Molecular and General Genetics 171, 229-238.

Cummings, D. J., Belcour, L. \& Grandchamp, C. (1979b). Mitochondrial DNA from Podospora anserina II. Properties of mutant DNA and multimeric circular DNA from senescent cultures. Molecular and General Genetics 171, 239-250.

Degn, H., LloYd, D. \& Hill, G. C. (1978). Functions of Alternative Terminal Oxidases. Oxford: Pergamon Press.

Edwards, D. L. \& RosenberG, E. (1976). Regula- tion of cyanide-insensitive respiration in Neurospora. European Journcl of Biochemistry 62, 217-221.

ESSER, K. (1974). Podospera anserina. In Handbook of Genetics, vol. 1, pp. 531-551. Edited by R. C. King. New York: Plenum Press.

HandLey, L. \& CATEN, C. E. (1973). Vegetative death: a mitochondrial mutation in Aspergillus amstelodami. Heredity 31, 136.

Holliday, R. (1969). Errors in protein synthesis and clonal senescence in fungi. Nature, London 221, 1224-1228.

Marcou, D. (1954). Sur le rajeunissement par le froid des souches de Podospora anserina. Comptes rendus hebdomadaire des séances de l'Académie des sciences 239, 1153-1155.

Marcou, D. (1961). Notion de longévité et nature cytoplasmique du déterminant de la sénescence chez quelques champignons. Annales des sciences naturelles, Botanique 11, 653-764.

Marcou, D. \& Schecroun, J. (1959). La sénescence chez Podospora anserina pourrait être du à des cytoplasmiques infectantes. Comptes rendus hebdomadaire des séances de l'Académie des sciences 248, 280-283.

RAYNAL, A. (1978). Etude des déterminants de sénescence et de longévité chez Podospora anserina: leur parenté et leurs relations avec les mitochondries. Thèse de IIIe cycle, Université Paris XI, France.

RIzeT, G. (1953). Sur la longévité des souches de Podospora anserina. Comptes rendus hebdomadaire des séances de l'Académie des sciences 237, 11061109. 
Rizet, G. (1957). Les modifications qui conduisent à la sénescence chez Podospora anserina sont-elles de nature cytoplasmique? Comptes rendus hebdomadaire des séances de l'Académie des sciences 244, 633-665.

Smith, J. R. \& Rubenstein, I. (1973a). The development of 'senescence' in Podospora anserina. Journal of General Microbiology 76, 283-296.

Smith, J. R. \& Rubenstein, I. (1973b). Cytoplasmic inheritance of the timing of 'senescence' in
Podospora anserina. Journal of General Microbiology 76, 297-304.

TudZYNSKI, P. \& EsSER, K. (1977). Inhibitors of mitochondrial function prevent senescence in the ascomycete Podospora anserina. Molecular and General Genetics 153, 111-113.

TUdzynski, P. \& Esser, K. (1979). Chromosomal and extrachromosomal control of senescence in the ascomycete Podospora anserina. Molecular and General Genetics 173, 71-84. 